Revista de

Contabilidade e

Organizações

www.rco.usp.br
DOI: http://dx.doi.org/10.11606/rco.v9i24.55524
Journal of

Accounting and

Organizations

www.rco.usp.br

\title{
Impacto das IFRS na assimetria de informação evidenciada no mercado de capitais brasileiro
}

Celso Vieira de Rezende ${ }^{a}$; Neirilaine Silva de Almeida ${ }^{a}$; Sirlei Lemes ${ }^{a}$

${ }^{a}$ Universidade Federal de Uberlândia

\section{Informações do Artigo}

Histórico do Artigo

Recebido: 10 de maio de 2013

Aceito: 12 de março de 2015

Palavras chave:

IFRS

Governança Corporativa

Assimetria de informação

\begin{abstract}
Resumo
Este estudo tem o objetivo de verificar os impactos da adoção das International Financial Reporting Standard (IFRS) na assimetria informacional no mercado de capitais brasileiro por meio de uma pesquisa descritiva com abordagem quantitativa e usando um levantamento de dados das empresas pertencentes ao Índice Bovespa (IBOVESPA) no período de 2008 a 2011. Utilizou-se regressão linear para verificar se a variação no spread de compra e venda era explicada pelas variáveis: nível de governança corporativa; divulgação de informações em consonância com as IFRS; negociação de American Depositary Receipt (ADR) na New York Stock Exchange (NYSE) e classificação como empresa Blue Chips. Verificou-se que apenas a adoção obrigatória das IFRS e o fato de a empresa ser considerada uma Blue Chips estavam relacionados com a redução da assimetria informacional nas empresas brasileiras abordadas na pesquisa.
\end{abstract}

Copyright (C) 2015 FEA-RP/USP. Todos os direitos reservados

\section{INTRODUÇÃ̃O}

Com o desenvolvimento de um ambiente empresarial cada vez mais competitivo e dinâmico, a obtenção de informações tempestivas e confiáveis, que auxiliem nas decisões organizacionais, tornou-se uma meta primordial. Esse cenário, em que a falta de informações relevantes é prejudicial aos agentes envolvidos no mercado, é propício à abordagem dos efeitos da assimetria informacional. Tal assimetria consiste na existência de um desequilíbrio na obtenção de informações, pelos envolvidos em determinada negociação comercial, que, além de ferir a igualdade das partes na operação, pode impactar o funcionamento do mercado (SCHETTINO, 2006; BRESSAN e BRESSAN, 2008; PIMENTA, 2009).

Pinto Júnior e Pires (2000) discorrem que em mercados que contemplam a disponibilização de informações de forma assimétrica, existe espaço para o comportamento oportunista, por parte dos agentes que detêm as informações mais relevantes sobre uma transação. Esse fato suscita a necessidade de atenuação da assimetria informacional. De fato, o acesso às informações é relevante para o sucesso da captação e aplicação de recursos no mercado. Assim, a melhor evidenciação contábil é um requisito necessário para suprir as necessidades dos usuários externos e atenuar a assimetria informacional entre os administradores de recursos e os investidores (OLIVEIRA e LEMES, 2011).

Para buscar atenuar o problema de assimetria informacional, alguns países, inclusive o Brasil, têm adotado práticas de Governança Corporativa (GC). Alguns esforços como os oriundos da Bolsa de Valores, Mercadorias \& Futuros de São Paulo (BM\&FBovespa), com a criação de níveis diferenciados de negociação para as empresas que se comprometem a seguir as melhores práticas de GC e do Instituto Brasileiro de Governança Corporativa (IBGC), com a divulgação de um código que norteia tais práticas, são exemplos do interesse do país na melhoria da transparência, da confiabilidade e da qualidade das informações.

Autor Correspondente: Tel (34) 3239-4411

E-mail: cvrezende@hotmail.com (C. V. Rezende); neiresa@gmail.com (N. S. Almeida); sirlemes@uol.com.br (S. Lemes)

Universidade Federal de Uberlândia - Av. João Naves de Ávila, 2121 - Bloco F - Sala 1F215 - Bairro Santa Mônica. Cep: 38.400-902 - Uberlândia, MG - Brasil. 
A negociação de títulos no exterior por intermédio dos American Depositary Receipt (ADR) é outro fator que amplia a transparência e melhora a qualidade das informações das empresas, em função das exigências de órgãos como a Securities and Exchange Comission (LIMA et al, 2008). Ademais, a pressão para a divulgação de informações relevantes por parte das empresas consideradas Blue Chips é crescente. Isso pode ser explicado pelo fato de as ações das referidas organizações despertarem a atenção dos investidores e se destacarem pela quantidade de negociações e de abordagens na mídia e nos ambientes de negócios (SOUZA e ROJO, 2010).

Para a Ernst \& Young e a FIPECAFI (2011), a adoção das International Financial Reporting Standard (IFRS) também pode contribuir com essa questão, pois tal conjunto de regras prioriza a busca pela mensuração da realidade econômica das entidades e exige o aumento da qualidade das informações divulgadas, fato que coopera com a redução da assimetria informacional existente entre a empresa e os usuários de suas informações.

No contexto brasileiro a criação do Comitê dos Pronunciamentos Contábeis (CPC) e as mudanças na Lei das Sociedades por Ações provenientes da promulgação da Lei n ${ }^{\circ}$ 11.638/07 e da Lei no 11.941/09 foram passos significativos para que o país entrasse, efetivamente, no processo de convergência internacional. Como resultado, em 2010, as empresas brasileiras passaram a utilizar pronunciamentos convergentes às IFRS, que visam à promoção de relatórios contábeis confiáveis, transparentes, comparáveis e que priorizam o atendimento das necessidades dos usuários externos, inclusive aumentando o nível de exigências na divulgação das informações.

Diante disso, esta pesquisa tem o objetivo de identificar os impactos da adoção das IFRS na assimetria informacional das empresas do mercado de capitais do Brasil pertencentes ao IBovespa. Considerando que, entre 2008 e 2011, as empresas brasileiras de capital aberto foram expostas à adoção obrigatória das IFRS, à entrada em grupos específicos de Governança Corporativa e à negociação de ADR na New York Stock Exchange (NYSE), estabeleceram-se, como passos auxiliares para responder à problemática da pesquisa, os seguintes objetivos específicos:

i. Verificar se a adoção das IFRS no Brasil diminuiu a assimetria de informações entre os participantes do mercado de capitais brasileiro;

ii. Avaliar se o comportamento da assimetria informacional nas empresas listadas no Novo Mercado é diferente do existente nas empresas que estão listadas em outros níveis de GC;

iii. Identificar se o comportamento da assimetria de informação nas empresas que negociam suas ações na NYSE é diferente daquele identificado nas empresas que não efetuam tal negociação;

iv. Comparar a assimetria de informação nas ações de empresas que são consideradas Blue Chips com as demais empresas.

Esse estudo se justifica pela possibilidade de verificar se as mudanças no cenário contábil brasileiro têm possibilitado a redução de um relevante problema para o mercado: a assimetria de informacional. Ademais, a avaliação do impacto da adoção das IFRS em empresas com níveis diferenciados de GC, com negociação de títulos em mercado internacional (NYSE) e com ações que possuem grande liquidez (Blue chips) também permite identificar se essas características empresariais contribuem para a atenuação da assimetria informacional. Por fim, a pesquisa amplia o conhecimento dos impactos das IFRS no mercado do país, o que pode ser útil para a melhoria da tomada de decisões por parte dos stakeholders e para o aumento do interesse de investidores no mercado de capitais brasileiro.

O artigo apresenta cinco seções. Após a introdução, a segunda seção caracteriza a assimetria de informação, o spread de compra e venda, as práticas de GC, as empresas consideradas Blue Chips e o processo de adoção das IFRS. A terceira seção trata dos procedimentos metodológicos. Na quarta e quinta seções, são apresentadas as análises e considerações finais sobre o assunto.

\section{FUNDAMENTAÇÃO TEÓRICA}

\subsection{Assimetria de Informação}

Pindyck (2002) afirma que em certas ocasiões, em que um dos agentes envolvidos numa operação no mercado detém o privilégio da exclusividade de alguma informação relevante em relação a outra parte da operação, observa-se um problema de assimetria informacional. Rover e Murcia (2010, p. 3) discorrem que a assimetria de informação ocorre, pois "os usuários internos estão mais informados, uma vez que têm acesso privilegiado às informações da organização”. Para Schettino (2006), a assimetria informacional pode ser considerada uma falha que, além de alterar o resultado de determinadas operações, pode influenciar significativamente o funcionamento 
do mercado. Afinal, tal assimetria propicia a existência da postura oportunista de determinados agentes, o que acarreta o surgimento de um mercado imperfeito e com altos custos de transação (CARVALHO et al, 2010).

A assimetria informacional provoca desconfianças que culminam no afastamento de investidores, na menor liquidez e na queda dos preços das ações (PATAH, 2012). O que ocorre é que, diante da referida assimetria, os investidores comumente "buscam uma proteção contra possíveis perdas resultantes de negociações com outros agentes mais bem informados, diminuindo o preço no qual estão dispostos a pagar por um título e/ou aumentando o preço exigido para vender seus títulos" (ROVER e MURCIA, 2010, p. 4). Tal postura origina uma diferença entre os preços de oferta e de procura, denominada bid-ask spread (também conhecida como spread de compra e venda).

O spread de compra e venda é visto como um aspecto de liquidez de mercado, uma vez que as ações de empresas com baixo nível informacional tendem a ter menor liquidez e a ficarem mais onerosas. Isso ocorre, pois, diante do menor nível de divulgação, os investidores podem supor que enfrentarão proteção nos preços no futuro e tal desconfiança gera a redução dos preços que eles estariam dispostos a pagar pelos títulos. Esse fato reduz a possibilidade de negociação e, em consequência, a liquidez das ações (WELKER, 1995; VERRECCHIA, 2001).

Ao abordar o tema, Mendonça Neto e Riccio (2008, p. 106) afirmam que "o bid-ask spread mede a firmeza do mercado que é uma das dimensões da liquidez. Quanto menor o spread mais firme será o mercado e, portanto menor o risco de liquidez sob este aspecto". Assim, é possível afirmar que quanto maior a assimetria informacional existente em um mercado maior será o bid-ask spread, o que ressalta a essencialidade de ações que atenuem essa desigualdade de informações, por meio de divulgações mais completas, claras e confiáveis.

Uma tentativa de melhorar a divulgação de informações é a utilização das práticas de GC, “que tem por finalidade otimizar o desempenho de uma companhia ao proteger todas as partes interessadas, tais como investidores, empregados e credores" (CVM, 2002, p. 1). Em 2000, a BM\&FBovespa estabeleceu segmentos diferenciados de GC. Tais segmentos referem-se ao Nível 1, Nível 2 e Novo Mercado e englobam as organizações que se comprometem, voluntariamente, a adotar as exigências pertinentes a cada segmento. Especificamente, o Novo Mercado é o segmento que contempla apenas as entidades que se empenhem em adotar o maior número de práticas de GC (SROUR, 2005). Esse foi um passo relevante no cenário brasileiro, pois autores, como Andrade e Rossetti (2004) e Vieira e Mendes (2006), defendem que as práticas de GC podem auxiliar o desempenho das empresas e propiciar vários benefícios para as entidades como a atenuação dos problemas entre os agentes (conflito de agência), a melhoria da qualidade das informações e a obtenção de maior segurança para a tomada de decisões. Em outras palavras, a adoção das melhores práticas de GC contribui com a redução da assimetria informacional, o que propicia maior segurança e transparência para os stakeholders (VIEIRA e MENDES, 2006).

Ademais, as empresas que negociam ADR nos Estados Unidos necessitam ampliar a divulgação de suas informações com o arquivamento do Formulário 20-F (Form 20-F) e o cumprimento das exigências dos órgãos norte-americanos, como a melhoria da qualidade da informação e o fornecimento de maior transparência de seus fatos relevantes (GARCIA, SATO e CASELANI, 2004; LIMA et al, 2008). As empresas que optaram, a partir de 2008, por apresentar as demonstrações contábeis em IFRS para aquele mercado também ficaram sujeitas a um nível maior de divulgação. Na prática o que se percebe é que as empresas brasileiras que negociam ADR na NYSE devem cumprir mais exigências quanto à divulgação de suas informações e, por isso, supõe-se que os usuários de seus relatórios podem ter acesso a maior número de fatos relevantes sobre a situação da empresa.

Em síntese, a assimetria informacional prejudica o bom desempenho do mercado, provoca custos de transação e reduz a liquidez dos títulos. Deduz-se, portanto, que a sua redução, por meio de melhores práticas de evidenciação das informações, deve ser buscada com ênfase.

\subsection{Normas Internacionais de Contabilidade}

A contabilidade desempenha papel relevante para a atenuação da assimetria informacional. Com o processo de convergência que culminou na adoção das IFRS, a possibilidade de mitigação da assimetria de informação ficou ainda maior, uma vez que tal padrão de contabilidade exige informações mais claras e compreensíveis que auxiliem os usuários em suas tomadas de decisões (NETO, DIAS e PINHEIRO, 2009).

No Brasil, o CPC foi criado com o intuito de emitir pronunciamentos convergentes com as IFRS e em 2010 as empresas brasileiras passaram a seguir o padrão internacional de contabilidade. Para a Ernst \& Young e a FIPECAFI (2011, p. 7), tal ano foi um “divisor de águas da contabilidade brasileira”. Segundos essas 
instituições, a mudança de uma contabilidade baseada em regras para uma baseada em princípios aumentou o grau de julgamento para a elaboração das demonstrações contábeis e, consequentemente, a responsabilidade dos profissionais contábeis. Esse aumento na qualidade e na quantidade de divulgações sobre políticas e estimativas tende a beneficiar os usuários dessas demonstrações.

Apesar dos benefícios do novo padrão contábil, as críticas ao processo do International Accounting Standards Board (IASB) e os obstáculos consideráveis à convergência lançam dúvidas sobre a efetividade do trabalho desse órgão. Nobes (2013) afirma que, apesar da informação corriqueira de que as IFRS são adotadas por mais de 100 países, isso não implica a iminente morte das diferenças contábeis internacionais e que formas distintas de implementação das IFRS e problemas de linguagem e de enforcement, dentre outros fatores, justificam a sobrevivência das diferenças internacionais.

Barth (2014) discute o problema de mensuração e aponta a necessidade de o FASB e o IASB especificarem em suas Estruturas Conceituais o objetivo da mensuração e de fornecerem uma estrutura conceitual para a mensuração contábil e uma base conceitual para a escolha entre bases de mensuração alternativas quando da emissão de padrões. Durocher e Gendron (2011) apontam que os usuários das demonstrações financeiras, principalmente o investidor, não são ouvidos sobre o ideal de comparabilidade do IASB. Zhang e Andrew (2010) apontam que a comparabilidade desejada pelo IASB na prática ainda é superficial, citando o caso das terras chinesas, que são, em sua essência econômica, um tipo especial de leasing, levando as companhias a reconhecêlas como ativos intangíveis.

Por outro lado, com base em autores que argumentam que as IFRS aumentam a transparência e que a adoção das IFRS tem consequências favoráveis ao mercado de capitais, incluindo redução dos custos de capital, aumento da liquidez, melhoria no ambiente informacional e aumento da comparabilidade dos relatórios contábeis, De Fond et al. (2015) encontraram que a adoção das IFRS reduziu o risco de quebra de empresas não financeiras, principalmente entre aquelas de ambientes pobres de informação e em países onde a adoção das IFRS resultou em mudanças maiores e mais confiáveis no GAAP local.

Fundamentam a convergência para as IFRS, o aumento da comparabilidade e da qualidade das informações financeiras, assim como a menor assimetria informacional e o maior interesse de investidores em adquirir ações das companhias (liquidez). De fato, Leuz e Verrecchia (2000) identificaram que a liquidez estava associada à adoção das normas internacionais por empresas da Alemanha. Entretanto, Daske et al. (2008), em uma análise com empresas de 26 países, identificaram que a liquidez das ações aumentou com a adoção das IFRS, mas apenas em países que possuem enforcement e incentivos para a transparência corporativa. Isso realça a heterogeneidade dos resultados sobre os impactos da adoção das IFRS na liquidez das ações e a necessidade de cautela para as interpretações referentes aos impactos desse padrão contábil no mercado de capitais (DASKE et al., 2013).

No que diz respeito à assimetria de informações, estudos em outros países evidenciaram que a adoção das IFRS reduziu a assimetria informacional (Leuz e Verrecchia, 2000; Muller, Riedl e Sellhorn, 2011). Esse aspecto foi um indício positivo, pois os investidores menos informados costumam ter receio de investir em um mercado em que desconhecem as informações relevantes para a tomada de decisão (HAIL, LEUZ e WYSOCKI, 2010). Com a elaboração de relatórios de acordo com as IFRS, há uma melhoria na evidenciação de informações relevantes tanto para os acionistas majoritários quanto para os minoritários. Dessa forma, a adoção das IFRS e a consequente redução da assimetria informacional são fatores importantes para o desenvolvimento do mercado de capitais.

Diante do exposto e apesar dos obstáculos ainda existentes ao processo de convergência num cenário mundial, percebe-se que o padrão internacional exige a apresentação de informações mais completas, o que pode contribuir para que os usuários das demonstrações financeiras consigam ter maior acesso a informações relevantes, confiáveis e comparáveis. Ademais, o aumento da qualidade dos relatórios contábeis, assim como a melhor e maior divulgação das informações são mudanças trazidas pelas IFRS para vários países que contribuem para a mitigação da assimetria informacional e para o aumento da liquidez das ações.

\section{ASPECTOS METODOLÓGICOS}

\subsection{Formulação das hipóteses, amostra e período amostral}

Para atender aos objetivos da pesquisa, efetuou-se um estudo descritivo e quantitativo, por meio de um 
levantamento de dados referentes ao Nível de GC, à divulgação de informações em consonância com as IFRS, à negociação de ADR na NYSE e à identificação das empresas Blue Chips. Os referidos dados foram obtidos nos sítios das bolsas de valores de São Paulo e de Nova Iorque.

Ademais, em consonância com o que foi exposto nas seções anteriores foram formuladas quatro hipóteses para verificar a possível existência de relação entre os níveis de assimetria informacional e as características referentes à adoção das IFRS, aos níveis de GC, às empresas classificadas como Blue Chips e à emissão de ADR, as quais estão elencadas a seguir:

- Hipótese alternativa 1 (H1): A adoção obrigatória das IFRS contribuiu para reduzir os níveis de assimetria de informação observados no mercado de capitais brasileiro.

A primeira hipótese está fundamentada nas exigências de maior divulgação de informações provenientes das IFRS, pois é esperado que após a adoção dessas normas o nível de assimetria informacional existente no mercado de capitais brasileiro tenha diminuído. Fernandes et al (2011, p. 3) ressaltaram essa expectativa de redução da assimetria informacional e Silva e Nardi (2014) discorreram que isso pode ocorrer, pois com a maior divulgação de informações da situação econômico-financeira das empresas, os investidores têm mais subsídios para tomar decisões com maior segurança.

- Hipótese alternativa 2 (H2): As empresas que possuem um nível de GC reconhecidamente mais elevado que outras, como o Novo Mercado da BM\&FBovespa, apresentam menor assimetria de informação que as demais participantes do mercado.

A literatura defende que as práticas de GC melhoram a qualidade das informações e a transparência das empresas, o que culmina na redução da assimetria informacional. Nascimento e Reginato (2008, p. 34), por exemplo, afirmam que "uma das formas de minimizar a assimetria de informação e os problemas de agência é a adoção de um sistema de governança corporativa”. Isso ocorre, pois a GC engloba práticas que transmitem segurança aos stakeholders da organização (NASCIMENTO e REGINATO, 2008).

- Hipótese alternativa 3 (H3): As empresas com atuação em mercados internacionais e com ações negociadas na NYSE, por meio de ADR, apresentam menor assimetria de informação que as demais participantes do mercado.

A terceira hipótese está em conformidade com o posicionamento de autores como Iquiapaza, Lamounier e Amaral (2008), que afirmam que uma empresa que emite ADR possui menor assimetria de informação que as empresas que não o fazem.

- Hipótese alternativa 4 (H4): As empresas com ações classificadas como Blue Chips apresentam menor assimetria de informação que as demais participantes do mercado.

O termo Blue chips é empregado nos mercados de ações, buscando designar ações das empresas mais bem cotadas na bolsa de valores, chamadas de "ações de primeira linha", ou seja, as ações com maior liquidez de mercado em função de serem as mais procuradas e com maior número de negócios realizados diariamente. Destaca-se que não há uma lista oficial dessas ações, pois essa resulta de um consenso do mercado financeiro (MUNDO TRADE, 2012).

De acordo com esses conceitos foi definido, para esta pesquisa, que para uma ação ser considerada uma blue chips deve simultaneamente:

- Fazer parte do grupo de $20 \%$ de ações que representavam $80 \%$ da composição do Índice Bovespa, no segundo quadrimestre de 2012. Tal critério pauta-se no princípio de Pareto, em que 20\% das causas explicam $80 \%$ dos problemas;

- Ser negociada na NYSE, por meio de ADR, para assegurar a atuação internacional da empresa.

A última hipótese supõe que as ações que possuem maior liquidez, medida por intermédio da maior participação no Índice Bovespa e participação no mercado internacional, medida por meio da participação na NYSE, são mais estudadas e visadas pela mídia para a divulgação de notícias e, por isso, apresentam menor assimetria informacional. De forma geral, assumem-se, como hipóteses de pesquisas, que as variáveis adoção das IFRS, nível de GC, emissão de ADR na NYSE e classificação como Blue Chips do mercado de capitais brasileiro têm relação com o nível de assimetria de informação.

No que diz respeito à amostra da pesquisa, destaca-se que ela é composta pelas 68 ações de empresas que participavam do Índice Bovespa (IBOVESPA ou IBOV) no dia 04 de maio de 2012. Como a análise do spread de compra e venda é realizada em função da variação do preço da ação da empresa, a amostra foi definida em termos 
de ação (ações-ano). Portanto as empresas que detêm mais de um tipo de ação pertencente ao IBOV, como é o caso de empresas como a Petrobras e Vale, participaram da amostra mais de uma vez por ano. Especificamente, o conceito de ações-ano, utilizado nesta pesquisa, foi estabelecido de forma análoga ao conceito de empresas-ano, instituído por Muller, Riedl e Sellhorn (2011) para justificar a participação de uma mesma empresa mais de uma vez na seleção da amostra.

Obtiveram-se dados de 68 ações em um período de quatro anos, perfazendo uma amostra potencial de 272 ações-ano (68 ações x 4 anos). Foram excluídas as ações que não participaram simultaneamente do conjunto formado pelas ações que participavam do IBOV $2^{\circ}$ quadrimestre 2012 e dos conjuntos das ações que participaram do IBOV $1^{\circ}$ quadrimestre 2008 a 2011, conforme mostra o diagrama de Venn apresentado na Figura 1. Dessa forma a amostra foi reduzida para 186 ações-ano.

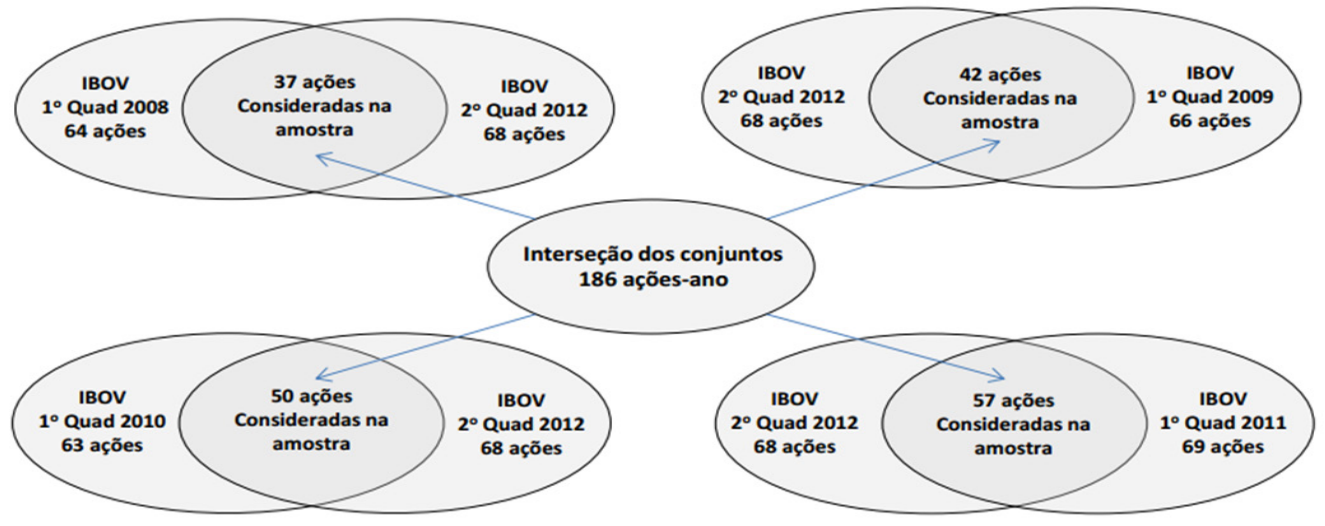

Figura 1. Diagrama de Venn usado na seleção da amostra

Ademais, a amostra composta por 186 ações-ano foi classificada em termos de participação em mercados específicos, conforme destacado no Quadro 1.

\begin{tabular}{l|c|c}
\hline \multicolumn{1}{c|}{ Amostra (ação-ano) } & Pré-IFRS & Pós-IFRS \\
\hline Mercado tradicional & 4 & 4 \\
\hline Nível N1 e N2 & 17 & 19 \\
\hline Novo Mercado (NM) & 20 & 40 \\
\hline Mercado tradicional e Mercado Internacional (NYSE) & 8 & 8 \\
\hline Nível N1 e N2 e Mercado Internacional (NYSE) & 22 & 23 \\
\hline Novo Mercado (NM) e Mercado Internacional (NYSE) & 8 & 13 \\
\hline Total de ações-ano & 79 & 107 \\
\hline
\end{tabular}

Quadro 1. Classificação da amostra

O período da amostragem, por sua vez, refere-se aos quatro anos compreendidos entre 2008 e 2011. Foram analisados os dois anos antes da adoção das IFRS no Brasil (2008 e 2009), denominado período Pré-IFRS, e os dois anos subsequentes à adoção obrigatória das referidas normas (2010 e 2011), definido como período Pós-IFRS. Destaca-se que as IFRS passaram a ser obrigatórias a partir de 2010, mas algumas empresas podem ter adotado tais normas, antecipadamente, no decorrer do ano de 2009.

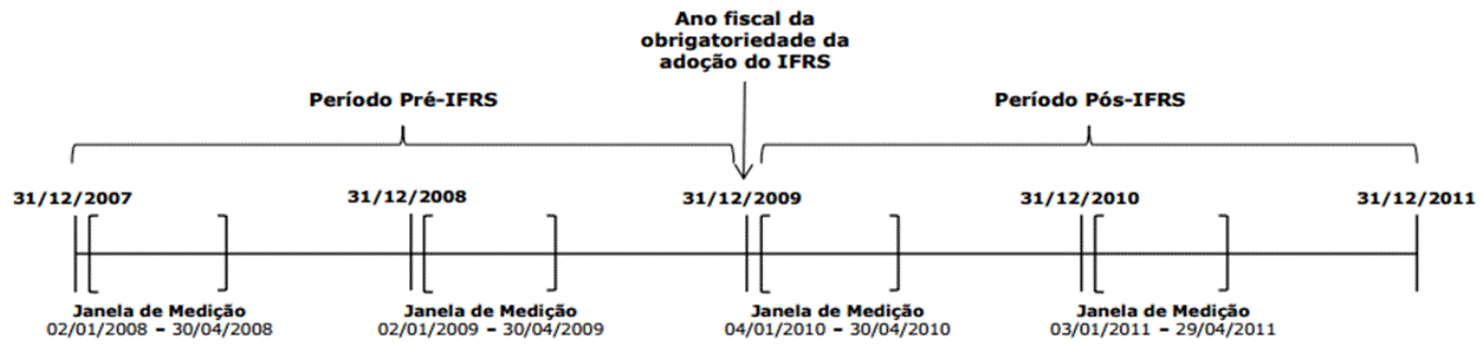

Figura 2. Janelas de medição nos períodos Pré-IFRS e Pós-IFRS

Fonte: Adaptado de Muller, Riedl e Sellhorn (2011) 
A Figura 2 mostra, em uma linha do tempo, as quatro janelas de medição, as quais sempre iniciam na data em que ocorreu o primeiro pregão do ano e terminam na data do último pregão do primeiro quadrimestre do ano. Esse intervalo de medição de quatro meses foi definido para coincidir com o período de vigência das ações que compõem o IBOVESPA. Ressalta-se que a análise deste trabalho fundamenta-se no estudo de Muller, Riedl e Sellhorn (2011), que abordou o comportamento da assimetria de informação em função da adoção da International Accounting Standard 40 - Investment Property.

\subsection{Modelagem Estatística}

Para testar as hipóteses, definidas no item anterior, a seguinte regressão foi estimada:

$$
\begin{aligned}
\log S P R E A D_{i t}= & \beta_{0}+\beta_{1} \log P R I C E_{i t}+\beta_{2} \log T U R N_{i t}+\beta_{3} \log R I S K_{i t}+ \\
& \beta_{4} \log I B O V_{i t}+\beta_{5} I F R S_{i t}+\beta_{6} N M_{i t}+\beta_{7} N Y S E_{i t}+ \\
& \beta_{8} B L U E_{i t}+\beta_{9}\left(I F R S_{i t} \times N M_{i t}\right)+\beta_{10}\left(I F R S_{i t} x N Y S E_{i t}\right)+ \\
& \beta_{11}\left(I F R S_{i t} \times B L U E_{i t}\right)+\tau_{i t}
\end{aligned}
$$

Na Equação 1 a variável dependente (SPREAD) e as variáveis de controle (PRICE, TURN, RISK e IBOV) foram transformadas em log para acomodar as relações de multiplicação na determinação do spread de compra e venda (STOLL, 1978). A transformação em log costuma ser utilizada em estudos que abordam o spread, pois simplifica os cálculos e tende a homogeneizar a variância da variável (SPRUGEL, 1983). Essas variáveis foram incluídas na Equação 1 para controlar os determinantes do spread de compra e venda, em consonância com Lee, Mucklow e Ready (1993) e Leuz e Verrecchia (2000). A descrição e função de cada variável de controle são relatadas no Quadro 2.

\begin{tabular}{c|l|l}
\hline Variável & \multicolumn{1}{|c}{ Descrição } & \multicolumn{1}{c}{ Função } \\
\hline Log SPREAD & $\begin{array}{l}\text { Logaritmo da empresa-ação i no ano t, significa a média } \\
\text { percentual do spread de compra e venda calculado } \\
\text { diariamente como a diferença entre a melhor oferta de } \\
\text { venda e a melhor oferta de compra, dividido pela média } \\
\text { desses dois valores. Valores diários são usados para calcular } \\
\text { a média dos 4 meses do primeiro quadrimestre de cada ano. }\end{array}$ & $\begin{array}{l}\text { Quantificar a assimetria de informação } \\
\text { nas ações em estudo. Na Equação 1 ela é } \\
\text { a variável dependente. }\end{array}$ \\
\hline \multirow{2}{*}{ Log PRICE $_{i t}$} & $\begin{array}{l}\text { Logaritmo da empresa-ação i no ano t, significa o preço de } \\
\text { fechamento da ação da empresa. Valores diários são usados } \\
\text { para calcular a média dos 4 meses do primeiro quadrimestre } \\
\text { de cada ano. }\end{array}$ & $\begin{array}{l}\text { Controlar os custos de ordens de compra } \\
\text { e venda dos formadores de mercado, } \\
\text { varia em direção contrária ao Log } \\
\text { SPREAD, ou seja, quanto maior o preço } \\
\text { da ação menor o spread de compra } \\
\text { e venda. Espera-se um coeficiente } \\
\text { negativo na regressão. }\end{array}$ \\
\hline Log TURN & $\begin{array}{l}\text { Logaritmo da empresa-ação i no ano t, significa o } \\
\text { percentual de ações da empresa em relação ao total de ações } \\
\text { negociadas por dia. Valores diários são usados para calcular } \\
\text { a média dos 4 meses do primeiro quadrimestre de cada ano. }\end{array}$ & $\begin{array}{l}\text { Controlar os custos de estocagem das } \\
\text { ações (manutenção em carteira) dos } \\
\text { formadores de mercado. Espera-se um } \\
\text { coeficiente negativo na regressão. }\end{array}$ \\
\hline Log IBOV & $\begin{array}{l}\text { Logaritmo da empresa-ação i no ano t, significa o desvio } \\
\text { padrão dos retornos diários das ações da empresa, calculado } \\
\text { nos 4 meses do primeiro quadrimestre de cada ano. }\end{array}$ & $\begin{array}{l}\text { Controlar os custos de estocagem das } \\
\text { ações (manutenção em carteira) dos } \\
\text { formadores de mercado. Espera-se um } \\
\text { coeficiente positivo na regressão. }\end{array}$ \\
\hline $\begin{array}{l}\text { Logaritmo da empresa-ação i no ano t, significa o } \\
\text { percentual que a ação da empresa representa no Índice } \\
\text { calculado como sendo a média dos 4 meses. }\end{array}$ & $\begin{array}{l}\text { Controlar o ambiente de informação da } \\
\text { empresa, pois uma maior participação da } \\
\text { ação no Índice Bovespa deveria reduzir a } \\
\text { assimetria de informação. Espera-se um } \\
\text { coeficiente negativo na regressão. }\end{array}$ \\
\hline
\end{tabular}

Quadro 2. Descrição das variáveis de controle da Equação 1

Adicionalmente algumas variáveis experimentais foram incluídas, com o objetivo de capturar mudanças na assimetria informacional por meio da variação do spread de compra e venda para os diferentes mercados nos períodos pré e pós-adoção obrigatória das IFRS. A descrição e função de cada variável de controle são apresentadas no Quadro 3. 


\begin{tabular}{|c|c|c|}
\hline Variável & Descrição & Função \\
\hline IFRS $_{i t}$ & $\begin{array}{l}\text { Variável binária que assume o valor igual a } 1 \text { para } \\
\text { a empresa i que apresentou os relatórios contábeis } \\
\text { no padrão IFRS no ano t e valor igual a } 0 \text { para as } \\
\text { demais situações. }\end{array}$ & $\begin{array}{l}\text { Verificar o efeito da adoção obrigatória das IFRS na } \\
\text { assimetria de informação das empresas pertencentes } \\
\text { à amostra. }\end{array}$ \\
\hline $\mathbf{N M}_{i t}$ & $\begin{array}{l}\text { Variável binária que assume o valor igual a } 1 \text { para } \\
\text { a empresa i que fez parte do Novo Mercado da } \\
\text { BM\&FBovespa no ano t, e valor igual a } 0 \text { para as } \\
\text { demais situações. }\end{array}$ & $\begin{array}{l}\text { Verificar se o fato das ações pertencerem a uma } \\
\text { empresa do Novo Mercado tem alguma relação } \\
\text { com a redução da assimetria de informação de suas } \\
\text { ações. }\end{array}$ \\
\hline NYSE $_{i t}$ & $\begin{array}{l}\text { Variável binária que assume o valor igual a } 1 \text { para } \\
\text { a empresa i que negociou ações na NYSE no ano t, } \\
\text { e valor igual a } 0 \text { para as demais situações. }\end{array}$ & $\begin{array}{l}\text { Verificar se o fato das ações da empresa serem } \\
\text { negociadas na NYSE tem alguma relação com a } \\
\text { assimetria de informação de suas ações. }\end{array}$ \\
\hline $\mathbf{B L U E}_{i t}$ & $\begin{array}{l}\text { Variável binária que assume o valor igual a } 1 \text { para } \\
\text { a empresa i que, simultaneamente, faz parte do } \\
\text { grupo de } 20 \% \text { de ações que representavam } 80 \% \text { da } \\
\text { composição do Índice Bovespa e negociou ações } \\
\text { na NYSE no ano t, e valor igual a } 0 \text { para as demais } \\
\text { situações. }\end{array}$ & $\begin{array}{l}\text { Verifica se o fato da empresa possuir maior liquidez } \\
\text { em suas ações e tiver seus títulos negociados no } \\
\text { mercado acionário de Nova Iorque tem alguma } \\
\text { relação com a assimetria de informação de suas } \\
\text { ações. }\end{array}$ \\
\hline $\mathbf{I F R S}_{i t} \times \mathbf{N M}_{i t}$ & $\begin{array}{l}\text { Variável binária que resulta do produto entre as } \\
\text { variáveis IFRS e NM da empresa i no ano t. }\end{array}$ & $\begin{array}{l}\text { Verifica o efeito da adoção obrigatória das IFRS nas } \\
\text { ações das empresas que estão no novo mercado da } \\
\text { BM\&FBovespa. }\end{array}$ \\
\hline IFRS $_{i t} \times$ NYSE $_{i t}$ & $\begin{array}{l}\text { Variável binária que resulta do produto entre as } \\
\text { variáveis IFRS e NYSE da empresa i no ano t. }\end{array}$ & $\begin{array}{l}\text { Verifica o efeito da adoção obrigatória das IFRS nas } \\
\text { ações das empresas que são negociadas na NYSE. }\end{array}$ \\
\hline $\operatorname{IFRS}_{i t} \times$ BLUE $_{i t}$ & $\begin{array}{l}\text { Variável binária que resulta do produto entre as } \\
\text { variáveis IFRS e BLUE da empresa i no ano t. }\end{array}$ & $\begin{array}{l}\text { Verifica o efeito da adoção obrigatória das IFRS nas } \\
\text { ações das empresas que, simultaneamente, fazem } \\
\text { parte do grupo de } 20 \% \text { de ações que representavam } \\
80 \% \text { da composição do Índice Bovespa e têm ações } \\
\text { negociadas na NYSE. }\end{array}$ \\
\hline
\end{tabular}

Quadro 3. Descrição das variáveis experimentais da Equação 1

\section{ANÁLISE DOS RESULTADOS}

As correlações existentes entre as variáveis que fazem parte da regressão, são expostas na Tabela 1.

Tabela 1. Correlação entre as variáveis de controle

\begin{tabular}{l|c|c|c|c|c}
\hline & SPREAD & PRICE & TURN & RISK & IBOV \\
\hline SPREAD & $100 \%$ & & & & \\
\hline PRICE & $-8 \%$ & $100 \%$ & & & \\
\hline TURN & $-29 \%$ & $-30 \%$ & $100 \%$ & & \\
\hline RISK & $17 \%$ & $-14 \%$ & $18 \%$ & $100 \%$ & \\
\hline IBOV & $-79 \%$ & $21 \%$ & $18 \%$ & $8 \%$ & $100 \%$ \\
\hline
\end{tabular}

A estatística descritiva das variáveis é apresentada na Tabela 2.

Tabela 2. Estatística descritiva das variáveis da Equação 1

\begin{tabular}{l|c|c|c|c|c|c|c}
\hline Variável & Média & Desvio Padrão & Mínimo & Q1 & Mediana & Q3 & Máximo \\
\hline Log SPREAD & $-2,4882$ & 0,2338 & $-3,2001$ & $-2,6076$ & $-2,4660$ & $-2,3126$ & $-2,0157$ \\
\hline Log PRICE & 1,3866 & 0,2920 & 0,4942 & 1,1918 & 1,4241 & 1,5726 & 2,2364 \\
\hline Log TURN & $-2,4580$ & 0,3393 & $-3,4722$ & $-2,6957$ & $-2,4379$ & $-2,1989$ & $-1,8177$ \\
\hline Log RISK & $-1,6179$ & 0,1677 & $-1,9838$ & $-1,7419$ & $-1,6308$ & $-1,4967$ & $-1,0348$ \\
\hline Log IBOV & $-1,9216$ & 0,3690 & $-2,7008$ & $-2,1876$ & $-2,0048$ & $-1,6666$ & $-0,7385$ \\
\hline IFRS & 0,5753 & 0,4956 & 0 & 0 & 1 & 1 & 1 \\
\hline NM & 0,4355 & 0,4972 & 0 & 0 & 0 & 1 & 1 \\
\hline NYSE & 0,4409 & 0,4978 & 0 & 0 & 0 & 1 & 1 \\
\hline BLUE & 0,2043 & 0,4043 & 0 & 0 & 0 & 0 & 1 \\
\hline IFRS x NM & 0,2849 & 0,4526 & 0 & 0 & 0 & 1 & 1 \\
\hline IFRS x NYSE & 0,2366 & 0,4261 & 0 & 0 & 0 & 0 & 1 \\
\hline IFRS x BLUE & 0,1075 & 0,3106 & 0 & 0 & 0 & 0 & 1 \\
\hline
\end{tabular}


A Tabela 3 apresenta o painel com a análise da variável dependente SPREAD com os seguintes grupos: amostra completa de todas as ações; apenas ações de empresas que participam do mercado tradicional da Bovespa; ações que participam dos níveis N1 e N2 de GC; ações que participam do Novo Mercado; ações que são negociadas na NYSE e ações classificadas como blue chips.

Tabela 3. Análise univariada (variável dependente SPREAD)

\begin{tabular}{l|c|c|c|c|c|c}
\hline \multirow{2}{*}{} & \multicolumn{2}{|c|}{ Pré-IFRS } & \multicolumn{2}{c|}{ Pós-IFRS } & \multicolumn{2}{c}{ Diferença (Pós - Pré) } \\
\cline { 2 - 7 } & $\mathbf{N}$ & Média & $\mathbf{N}$ & Média & Mudança & Variação \% \\
\hline Amostra & 79 & $0,46 \%$ & 107 & $0,30 \%$ & $-0,16 \%$ & $-34,53 \%$ \\
\hline Tradicional & 12 & $0,36 \%$ & 12 & $0,25 \%$ & $-0,10 \%$ & $-28,98 \%$ \\
\hline Nov e N2 & 39 & $0,43 \%$ & 42 & $0,31 \%$ & $-0,12 \%$ & $-28,52 \%$ \\
\hline Internacional & 38 & $0,38 \%$ & 44 & $0,28 \%$ & $-0,10 \%$ & $-26,87 \%$ \\
\hline Blue Chips & 18 & $0,24 \%$ & 20 & $0,18 \%$ & $-0,06 \%$ & $-23,27 \%$ \\
\hline
\end{tabular}

Observa-se que todos os grupos de ações apresentaram reduções das médias da variável SPREAD após a adoção das IFRS. Especificamente, destaca-se que no período anterior à adoção das IFRS as empresas do Novo Mercado tinham o maior SPREAD médio (0,55\%) e, após a adoção das IFRS, elas apresentaram 43,78\% de redução do SPREAD médio, sendo que esse foi o maior percentual de redução dentre os grupos da amostra. No que se refere às empresas blue chips, elas apresentaram a menor média do SPREAD $(0,24 \%)$ e também a menor redução do SPREAD $(23,27 \%)$ após o uso do novo padrão contábil.

A Tabela 4 apresenta o resultado da análise de regressão usando o método dos mínimos quadrados, de acordo com a Equação 1. A variável dependente é o Log SPREAD, e os coeficientes se referem às variáveis de controle (Log PRICE, Log TURN, Log RISK e Log IBOV) e experimentais (IFRS, NM, NYSE, BLUE, IFRS x NM, IFRS x NYSE e IFRS x BLUE). Também são apresentadas as medidas de erro padrão, estatística $t$ e valor-p, bem como a exponencial da variável na base $e(2,7182)$ e a variação percentual.

Tabela 4. Análise multivariada (variável dependente Log SPREAD)

\begin{tabular}{l|c|c|c|c|c|c}
\hline \multicolumn{1}{c|}{ Variável } & Coeficientes & Erro padrão & Estatística-t & Valor-P & Exponencial & Variação \\
\hline Interseção & $-3,47818$ & 0,11003 & $-31,61216$ & 0,00000 & & \\
\hline PRICE & 0,05474 & 0,02927 & 1,87038 & 0,06311 & 1,05627 & $5,6 \%$ \\
\hline TURN & $-0,10370$ & 0,02580 & $-4,01910$ & 0,00009 & 0,90149 & $-9,9 \%$ \\
\hline RISK & 0,04426 & 0,06226 & 0,71086 & 0,47812 & 1,04525 & $4,5 \%$ \\
\hline IBOV & $-0,45253$ & 0,03136 & $-14,42945$ & 0,00000 & 0,63601 & $-36,4 \%$ \\
\hline IFRS & $-0,21472$ & 0,03026 & $-7,09471$ & 0,00000 & 0,80677 & $-19,3 \%$ \\
\hline NM & 0,00145 & 0,02657 & 0,05448 & 0,95662 & 1,00145 & $0,1 \%$ \\
\hline NYSE & $-0,02562$ & 0,02812 & $-0,91110$ & 0,36350 & 0,97471 & $-2,5 \%$ \\
\hline BLUE & $-0,10471$ & 0,04212 & $-2,48571$ & 0,01387 & 0,90059 & $-9,9 \%$ \\
\hline IFRS x NM & $-0,00330$ & 0,03379 & $-0,09780$ & 0,92220 & 0,99670 & $-0,3 \%$ \\
\hline IFRS x NYSE & 0,04220 & 0,03721 & 1,13409 & 0,25832 & 1,04311 & $4,3 \%$ \\
\hline IFRS x BLUE & 0,07143 & 0,04696 & 1,52092 & 0,13010 & 1,07404 & $7,4 \%$ \\
\hline
\end{tabular}

As medidas de ajuste do modelo são expostas na Tabela 5. Os resultados encontrados para o R Múltiplo (91\%), R $(82 \%), \mathrm{R}^{2}$ ajustado (81\%) e Erro Padrão (10\%) indicam que a variável dependente é fortemente explicada pelas variáveis independentes.

Tabela 5. Medidas de ajuste da regressão

\begin{tabular}{l|c|c}
\hline R múltiplo & 0,90727 & $91 \%$ \\
\hline R-Quadrado & 0,82313 & $82 \%$ \\
\hline R-quadrado ajustado & 0,81195 & $81 \%$ \\
\hline Erro padrão & 0,10139 & $10 \%$ \\
\hline Observações & 186 & \\
\hline
\end{tabular}


Observa-se que ocorreu a redução na média geométrica da variável dependente SPREAD de 19,3\% após a adoção das IFRS, assim como houve reduções de 9,9\% nas Blue chips e 2,5\% nas empresas que negociam no mercado internacional (NYSE). Contudo, a mesma ocorrência não pode ser destacada para as empresas que participam do Novo Mercado, uma vez que a média geométrica desse grupo não apresentou redução.

Para verificar a rejeição das hipóteses estabelecidas inicialmente, realizou-se a análise conjunta das tabelas, conforme exposto na sequência:

- Hipótese alternativa $1\left(\mathbf{H}_{1}\right)$ : A adoção obrigatória das IFRS contribuiu para reduzir os níveis de assimetria de informação observados no mercado de capitais brasileiro.

Os resultados apresentados na análise univariável (Tabela 3) indicam que, considerando um nível de significância de 5\%, essa hipótese não pode ser rejeitada. Especificamente as ações foram reunidas em grupos que representam: a amostra completa de todas as ações; apenas as ações de empresas que participam do mercado tradicional da Bovespa; as ações que participam dos níveis N1 e N2 de GC; ações que participam do Novo Mercado; as ações que são negociadas na NYSE e as ações classificadas como Blue Chips. Em todos esses grupos foi possível evidenciar entre os períodos pré e pós-adoção das IFRS no Brasil uma significativa redução da média da variável SPREAD, a qual reflete os custos associados à assimetria de informação.

Ademais, tal constatação é confirmada pelo resultado da regressão linear refletida na variável experimental IFRS (Tabela 5) que apresentou resultado estatisticamente significante (coeficiente $=-0,21472$; estatística- $\mathrm{T}=-7,09471$; valor-P $=0,0000)$ e evidenciou que houve redução na média geométrica da variável dependente SPREAD de 19,3\% com a adoção das IFRS. Destaca-se que, em função das variáveis (dependente e de controles) terem sido Log transformadas a interpretação dos coeficientes da regressão deve referenciar a média geométrica (MULLER, RIEDL e SELLHORN, 2011).

- Hipótese alternativa $2\left(\mathbf{H}_{2}\right)$ : As empresas que possuem um nível de GC reconhecidamente mais elevado que outras, como o Novo Mercado da BM\&FBovespa, apresentam menor assimetria de informação que as demais participantes do mercado.

Os resultados da regressão linear proposta na Equação 1 para a variável experimental NM não apresentaram valor estatisticamente significante (coeficiente $=0,00145$; estatística- $\mathrm{T}=0,05447$; valor-P $=$ 0,95662 ), conforme mostra a Tabela 5, sugerindo que não houve alteração na média geométrica da variável dependente SPREAD para a amostra de ações de empresas que pertenciam ao Novo Mercado e para aquelas que não faziam parte desse segmento. A Tabela 5 ainda indica que as ações das empresas do Novo Mercado possuem média geométrica do spread de compra e venda 0,1\% superior às demais ações da amostra.

Diante dessas constatações essa hipótese deve ser rejeitada (nível de significância de 5\%), pois não foi possível comprovar que as ações pertencentes a esse grupo possuem alguma diferenciação quanto ao nível de assimetria de informação. Essa decisão também pode ser suportada pela análise univariável (Tabela 3), em que é possível identificar que essas ações possuíam um nível de assimetria informacional superior à média da amostra (SPREAD médio no período pré-IFRS de $0,55 \%$ para ações do Novo Mercado contra $0,46 \%$ referentes às ações de toda a amostra). Porém, baseado na mesma análise univariável, é possível identificar que esse grupo de ações foi o mais sensível à adoção das IFRS ao apresentar uma redução de 43,78\% na média do SPREAD em uma comparação entre o período pré-IFRS e pós-IFRS.

- Hipótese alternativa 3 (H3): As empresas com atuação em mercados internacionais e com ações negociadas na NYSE, por meio de ADR, apresentam menor assimetria de informação que as demais participantes do mercado.

Os resultados encontrados para NYSE (coeficiente $=-0,02562$; estatística-T $=-0,91110$; valor-P $=0,36350$ ), conforme mostra a Tabela 5 , indicaram que não houve diferenças estatisticamente significantes. Ainda assim foi possível concluir que esse grupo de ações apresenta média geométrica da variável dependente SPREAD 2,5\% menor que as demais ações da amostra. Portanto, não houve redução significativa de assimetria de informação em função de o título ser negociado no mercado internacional e, consequentemente, essa hipótese deve ser rejeitada (nível de significância de 5\%).

- Hipótese alternativa 4 (H4): As empresas com ações classificadas como Blue Chips apresentam menor assimetria de informação que as demais participantes do mercado.

A variável experimental BLUE foi incluída na regressão para sustentar essa hipótese e os resultados encontrados foram estatisticamente significativos (coeficiente $=-0,10471$; estatística- $\mathrm{T}=-2,48571$; valor-P $=0,01387$ ), conforme mostra a Tabela 5. Esses valores indicam que as ações que fazem parte desse grupo apresentam média geométrica da variável dependente SPREAD 9,9\% inferior à média geométrica das demais 
ações da amostra.

Em função desse resultado, respeitando o nível de significância de 5\%, é possível afirmar que essa hipótese não deve ser rejeitada, pois a análise univariável mostra que as ações desse grupo apresentaram os menores índices de assimetria de informação de toda a amostra.

\section{CONSIDERAÇÕES FINAIS}

Esta pesquisa se propôs a estudar os impactos da adoção obrigatória das IFRS na assimetria de informação, a qual pode ser mensurada pelo spread de compra e venda. Para tanto, uma amostra das ações das empresas de maior relevância no mercado de capitais brasileiro, componentes do IBovespa, foi escolhida para compor a base de dados.

Foram elaboradas quatro hipóteses para atender ao objetivo da pesquisa, das quais duas não foram rejeitadas e duas foram rejeitadas. Especificamente, os resultados indicaram que, no cenário em que as empresas brasileiras passaram a operar sob as regulamentações estabelecidas pelas IFRS, a partir de 2010, houve a redução dos níveis perceptíveis de informações divergentes entre compradores e vendedores, ou seja, da assimetria de informação (Hipótese 1). Considerando apenas as empresas Blue chips, a atenuação da assimetria informacional após a adoção das IFRS também foi visível (Hipótese 4). Percebeu-se, com esses resultados, uma semelhança com os achados em estudos de outros países como os de Leuz e Verrecchia (2000) e de Muller, Riedl e Sellhorn (2011) e uma indicação de que a adoção das IFRS contribuiu para a redução da assimetria em países com mercados de capitais distintos.

Essa constatação contribui para a avaliação do assunto, pois aponta que a adoção das IFRS proporcionou um ambiente com maior evidenciação de informações relevantes e uma redução dos oportunismos por parte de investidores que anteriormente poderiam ter informações privilegiadas. Ademais, como o Brasil é um país com alta concentração acionária, essa redução da assimetria informacional é ainda mais significativa, pois pode proporcionar maior confiança aos investidores e, consequentemente, contribuir para o fortalecimento do mercado de capitais do país.

Por outro lado, os resultados também indicaram que as empresas listadas no Novo Mercado da BM\&FBovespa não apresentaram redução estatisticamente superior aos demais participantes do mercado (Hipótese 2) e apresentaram SPREAD médio após a adoção das IFRS de 0,31\%, mesmo percentual das empresas Nível 1 e Nível 2.

De forma análoga, as organizações listadas na NYSE também não tiveram redução de assimetria informacional mais significativa que as demais empresas (Hipótese 3). Uma das explicações para esse resultado consiste no fato de que essas empresas já apresentavam menor assimetria informacional antes da adoção das IFRS, provavelmente em função de seguirem as exigências de evidenciação para negociação no mercado internacional.

Esta pesquisa se limitou pela seleção da amostra. Portanto, sugerem-se, para pesquisas futuras, a utilização de maior quantidade de ações-anos, além de outras variáveis, como a comparação de empresas de diversos setores para ampliar a análise da redução da assimetria informacional no mercado de capitais brasileiro.

\section{REFERÊNCIAS}

ANDRADE, A; ROSSETTI, J. P. Governança Corporativa - Fundamentos, desenvolvimento e tendências. São Paulo: Atlas, 2004.

BARTH, M. E. Measurement in Financial Reporting: the need for concepts. Accounting Horizons. v. 28, n. 2 , p. 331-352, 2014.

BM\&FBOVESPA. BOLSA DE VALORES, MERCADORIAS \& FUTUROS DE SÃO PAULO. Disponível em: http://www.bmfbovespa.com.br/cis-listadas/empresas-listadas/BuscaEmpresaListada.aspx?Idioma=ptbr. Acesso em 19 mai 2012. 
BRESSAN, V. G. F.; BRESSAN, A. A. Existe diferença entre a rentabilidade das ações das empresas que adotam governança corporativa com relação às empresas do mercado tradicional? Organizações Rurais \& Agroindustriais, v. 10, n. 2, p. 250-263, 2008.

CARVAlHO, N.; MARTINHAGO, D. Z.; ROCHA, C. T.; MELO, L. Q. Efeitos da Assimetria de Informação sobre os Custos de Transação da Cadeia Produtiva da Batata. In: VII SIMPÓSIO DE EXCELÊNCIA EM GESTÃO E TECNOLOGIA, Rio de Janeiro, 2010.

CVM. COMISSÃO DE VALORES MOBILIÁRIOS. Recomendações da CVM sobre Governança Corporativa. 2002. Disponível em: http://www.cvm.gov.br/port/public/publ/cartilha/cartilha.doc. Acesso em: 24 mai 2012

DASKE, H., HAIL, L., LEUZ, C., VERDI, R. Mandatory IFRS Reporting around the world: early evidence on the economic consequences. Journal of Accounting Research, v. 46, n. 5, p. 1085- 1142, 2008.

DASKE, H., HAIL, L., LEUZ, C., VERDI, R. Adopting a Label: Heterogeneity in the Economic Consequences Around IAS/IFRS Adoptions. Journal of Accounting Research, v. 51, n. 43, p. 495-547, 2013.

DE FOND M. L.; HUNG, M.; LI S.; LI, Y. Does Mandatory IFRS Adoption Affect Crash Risk. Accounting Review, v. 90, n. 1, p. 265-299, 2015.

DUROCHER, S.; GENDRON, Y. IFRS: On the Docility of Sophisticated Users in Preserving the Ideal of Comparability. European Accounting Review. v. 20, n. 2, p. 233-262, 2011.

ERNST \& YOUNG; FIPECAFI. IFRS: $1^{0}$ ano - Análises sobre a Adoção Inicial do IFRS no Brasil. 2011. Disponível em: http://mrm.comunique-se.com.br/arq/121/arq_121_219638.pdf. Acesso em: 30 de ago. 2015.

FERNANDES, B. V. R.; LIMA, D. H. S.; VIEIRA, E. T.; NIYAMA, J. K. Análise da percepção dos docentes dos cursos de graduação em ciências contábeis do Brasil quanto ao processo de convergência às Normas Internacionais de Contabilidade aplicadas no Brasil. Revista de Contabilidade e Controladoria., v. 3, n. 3, p. 24-50, 2011.

GARCIA, F. G.; SATO, L. G.; CASELANI, C. N. O impacto da política de transparência sobre o valor das empresas brasileiras. In: IV ENCONTRO BRASILEIRO DE FINANÇAS, Rio de Janeiro, 2004.

HAIL, L., LEUZ, C., WYSOCKI, P. Global accounting convergence and the potential adoption of IFRS by the U.S. (Part I): Conceptual underpinnings and economic analysis. Accounting Horizons, v. 24, n. 3. p. 355 394,2010

IQUIAPAZA, R. A.; LAMOUNIER, W. M.; AMARAL, H. F. Assimetria de Informações e Pagamento de Proventos em Dinheiro na Bovespa. Advances in Scientific and Applied Accounting, v. 1, n. 1, p. 1-15, 2008.

LEE, C. M. C.; MUCKLOW, B.; READY, M. J. Spreads, depths, and the impact of earnings information: An intraday analysis. Review of Financial Studies, v. 6, n. 2, p. 345-374, 1993.

LEUZ, C. IAS versus U.S. GAAP: Information asymmetry-based evidence from Germany's new market. Journal of Accounting Research, v. 41, n. 3, p. 445-472, 2003.

LEUZ, C., VERRECCHIA, R. E. The economic consequences of increased disclosure. Journal of Accounting Research, v. 38, p. 91-124, 2000.

LIMA, G.A.S.F.; YAMAMOTO, M. M.; LIMA, I.S.; MALACRIDA, M. J. C. Um estudo da eficiência informacional do mercado acionário brasileiro. Revista de Informação Contábil, v. 2, n. 1, p. 1-18, 2008.

MENDONÇA NETO, O. R.; RICCIO, E, L. A qualidade da informação contábil e o risco de liquidez de mercado. Organizações em Contexto, v. 4, n. 8, p. 100-120, 2008.

MULLER, K. A.; RIEDL, E. J.; SELLHORN, T. Mandatory Fair Value Accounting and Information Asymmetry: Evidence from the European Real Estate Industry. Management Science, v. 57, n. 6, p. 1138-1153, 2011.

MUNDO TRADE. O que são ações Blue Chips? Disponível em: http://www.mundotrade.com.br/acoes-bluechips. Acesso em: 23 jun 2012.

NASCIMENTO A. M.; REGINATO, L. Divulgação da informação contábil, governança corporativa e controle organizacional: uma relação necessária. Revista Universo Contábil, v. 4, n. 3, p. 25-47, 2008. 
NETO, J. E. B.; DIAS, W. de O.; PINHEIRO, L. E. T. Impacto da Convergência para as IFRS na Análise Financeira: um Estudo em Empresas Brasileiras de Capital Aberto. Contabilidade Vista \& Revista, v. 20, n. 4, p. 131-153, 2009.

NOBES, C.W. The continued survival of international differences under IFRS. Accounting and Business Research, v. 43, n. 2, p. 83-111, 2013.

OLIVEIRA, V. A.; LEMES, S. Nível de convergência dos princípios contábeis brasileiros e norte-americanos às normas do IASB: uma contribuição para a adoção das IFRS por empresas brasileiras. Revista Contabilidade \& Finanças, v. 22, n. 56, p. 155-173, 2011.

PATAH, J. R. K. Concentração do controle, governança corporativa e o impacto na liquidez das ações de empresas brasileiras. 2012. 43f. Dissertação (Mestrado em Finanças e Economia) - Escola de Economia de São Paulo da Fundação Getúlio Vargas, São Paulo, 2012.

PIMENTA, S. G. Assimetria da informação e a gestão do conhecimento estratégico em processos regulatórios, Transinformação, v. 21, n. 2, p. 99-116, 2009.

PINDYCK, R. S. Microeconomia. 5. ed. São Paulo: Prentice Hall, 2002.

PINTO JÚNIOR, H. Q.; PIRES, M. C . P. Assimetria de informações e problemas regulatórios. Nota Técnica, n. 9 , fev. 2000.

ROVER, S.; MURCIA, F. D. Influencia do disclosure voluntário econômico e socioambiental no custo de capital próprio de empresas brasileiras. In: IV CONGRESSO ASSOCIAÇÃO NACIONAL DOS PROGRAMAS DE PÓS GRADUAÇÃO EM CIÊNCIAS CONTÁBEIS - ANPCONT, Natal, 2010.

SCHETTINO, T. S. Inclusão Social e “Assimetria de Informação” no Sistema de Ensino Superior Brasileiro - Uma análise comparativa. Dissertação (Mestrado em Sociologia e Antropologia) - Instituto de Filosofia e Ciências Sociais da Universidade Federal do Rio de Janeiro, Rio de Janeiro, 2006.

SILVA, R. L. M.; NARDI, P. C. C. Demonstrações Contábeis no Brasil após Adoção do CPC 13: reação do mercado de ações. Advances in Scientific and Applied Accounting, v. 7, n. 3, p. 362-385, 2014.

SOUZA, A. F. ; ROJO, C. A. Análise de Investimentos por Simulação de Cenários Baseada em Variáveis Críticas Qualitativas Compiladas com Lógica Fuzzy. Revista CAP, v. 4, n. 4, p. 118-126, 2010.

SPRUGEL, D. G. Correcting for Bias in Log-Transformed Allometric Equations. Ecology, v. 64, n. 1, p. 209210,1983 .

SROUR, G. Práticas diferenciadas de governança corporativa: um estudo sobre a conduta e a performance das firmas brasileiras. Revista Brasileira de Economia, v. 59, n. 4, p. 635-674, 2005.

STOLL, H. R. The Supply of Dealer Services in Securities Markets, Journal of Finance, v. 33, n. 4, p. 1133$1151,1978$.

VERRECCHIA, R. E. Essays on disclosure. Journal of Accounting and Economics, v. 32, n. 1-3, p. 97-180, 2001.

VIEIRA, S. P.; MENDES, A. G. S. T. Governança corporativa: uma análise de sua evolução e impactos no mercado de capitais brasileiro. Organizações em Contexto, v. 2, n. 3, p. 48-67, 2006.

WELKER, M. Disclosure policy, information asymmetry, and liquidity in equity markets. Contemporary Accounting Research, v. 11, n. 2, p. 801-827, 1995.

ZHANG, Y., ANDREW, J. Land in China: Re-considering comparability in financial reporting. Australasian Accounting, Business and Finance Journal, v. 4, n. 1, p. 53-75, 2010. 